\title{
Article
}

\section{Neuroethics for Fantasyland or for the Clinic? The Limitations of Speculative Ethics}

\author{
SVEN OVE HANSSON
}

\begin{abstract}
What purpose can be served by empirically unsubstantiated speculation in ethics? In answering that question, we need to distinguish between the major branches of ethics. In foundational moral philosophy, the use of speculative examples is warranted to the extent that ethical principles and theories are assumed to be applicable even under the extreme circumstances referred to in these examples. Such an assumption is in need of justification, and it cannot just be taken for granted. In applied ethics, the use of unrealistic scenarios is more difficult to justify. It can be positively harmful if it diverts our attention from more urgent issues. Neuroethics is one of the areas of applied ethics where speculative scenarios have taken up much of the attention that could instead have been devoted to problems that are relevant for the treatment and care of patients. Speculative ethics has often been defended with mere possibility arguments that may at first hand seem difficult to refute. It is shown with examples how such claims can be defeated with a combination of science and argumentation analysis.
\end{abstract}

Keywords: neuroethics; applied ethics; speculation; mere possibility arguments; speculative examples; unrealistic scenarios

\section{Introduction}

Philosophy, perhaps in particular moral philosophy, differs from other academic disciplines in its profuse and unabashed use of examples that are empirically implausible, sometimes even physically impossible. As Philip Abbot noted:

\begin{abstract}
"But what examples! The world of the philosopher is filled with people spores, child missile launchers, Martians, talking robots, talking dogs, kittens, chimps, jig [s]aw cells that form human beings, transparent wombs, and cool hands - everything in fact but fetuses growing in wombs and infants cradled in parents' arms... Philosophers have moved into the world of fantasy in the same way and with the same verve that social scientists moved into the world of quantifiable facts... It is very questionable whether the moral dimensions of our lives can be clarified in circumstances in which the very basis for morality is no longer present.."1
\end{abstract}

This is a tendency that seems to have escalated in recent decades. As several authors have noted, it appears to be particularly strong in neuroethics. ${ }^{2}$ However, it has also repeatedly been subject to critical comments. ${ }^{3}$ It is the purpose of this article to clarify what types of criteria we should apply in distinguishing between irrelevant speculative scenarios and useful thought experiments. In doing so, we need to distinguish between the two major areas of ethical discourse, namely, on the one

Acknowledgement: Work with this article was supported by the Swedish Research Council, grant 201407483. I would like to thank Frederic Gilbert, Gert Helgesson, Niklas Juth, Niels Lynöe, and Tomas Månsson for valuable comments on an earlier version.

Cambridge Quarterly of Healthcare Ethics (2020), 29, 630-641.

(C) The Author(s), 2020. Published by Cambridge University Press. This is an Open Access article, distributed under the terms of the Creative Commons Attribution-NonCommercial-NoDerivatives licence (http:// creativecommons.org/licenses/by-nc-sa/4.0/), which permits non-commercial re-use, distribution, and reproduction in any medium, provided the original work is unaltered and is properly cited. The written permission of Cambridge University Press must be obtained for commercial re-use or in order to create a derivative work. 
hand, foundational moral philosophy and on the other, applied ethical disciplines such as neuroethics.

The word "speculate" entered the English language in the late 16th century as a synonym of "contemplate" or "theorize." Today, it is usually employed in a derogatory sense about thoughts or discussions "of a conjectural or theoretical nature. ${ }^{\prime 4}$ In discussions on philosophical style, it refers to claims or arguments that are based on implausible or unrealistic assumptions. Perhaps a less pejorative terminology, referring to "unrealistic," "fictional," or "imaginative," rather than "speculative" thoughts and examples, would have been preferable, but no attempt at terminological reform will be made here.

We will now turn to an analysis of the uses of empirically unsubstantiated speculation in foundational moral philosophy. It concludes with recommendations on the sound use of such speculation. After that, the use of speculative examples in applied ethics will be briefly introduced, followed by a critical analysis of the major argumentative patterns that have been offered in defense of such examples. Finally, this will all be brought to bear on current developments in neuroethics, which is one of the areas of applied ethics that are most affected by speculative examples and scenarios.

\section{Foundational Moral Philosophy}

General or foundational moral philosophy, as it is taught and researched primarily in departments of philosophy, is usually devoted to discussions on ethical theories. By an ethical theory (in a wide sense), we mean a general approach to moral assessment that is intended to serve as a framework guiding moral decisions in the various situations that moral agents may encounter.

There is an obvious, and basically sound, answer to the question what types of examples or scenarios are relevant for the evaluation or development of a theory: an example is relevant if and only if it concerns events or situations falling within the scope that the theory is intended to cover. We can call this the scope criterion. It applies to all kinds of theories: empirical, metaphysical, normative, evaluative, etc. theories. For instance, a theory about the flight of birds cannot be confirmed or disconfirmed by investigations of flight patterns in butterflies (but, of course, such investigations are relevant for possible extensions of the theory to cover these creatures as well). For the same obvious reasons, an ethical example concerning potential beings that differ from us humans in ways that are crucial for the example cannot be used to confirm or disconfirm an ethical theory whose scope is limited to human beings.

Although the scope criterion is simple and arguably trivial, its application to ethical theories is often difficult. Instead, it is common to implicitly assume that moral theories are limitless in the sense of applying to all kinds of creatures and situations that we can at all imagine. Consequently, there is no principled way to exclude the use even of examples that are so far-fetched that it is difficult to see how we can at all have intuitions about them. This limitless approach to the scope of moral theories is closely connected with two other, important but seldom discussed, assumptions.

The first and most fundamental of these assumptions is that moral philosophy deals with moral principles and theories that hold not only in human societies as we know them, but also under virtually all imaginable conditions where intelligent entities make choices. Moral theories such as utilitarianism are commonly taken to have such a wide scope of application, but this is a grand ambition rather than a reasoned conclusion, and it can certainly be questioned. ${ }^{5}$ With a more restricted 
scope for our moral principles and theories, many of the speculative examples will become irrelevant. For instance, if our notion of personal identity is supposed to cover all conceivable conscious entities, then it can be swayed by examples involving uploaded, duplicated, and teletransported minds. But if we restrict its scope to creatures of the types known to us, then such counterexamples will have no bearing on the concept.

The second assumption is that our methods for analyzing moral examples are sufficiently reliable also when applied to this kind of examples. Since the analysis of moral examples ultimately relies on our moral intuitions, this amounts to an assumption that these intuitions are sufficiently reliable also when exposed to bizarre and unheard of examples. This is questionable, not least since our moral concepts have been shaped to deal with the types of moral choices and standpoints that we may encounter in real life. W.V. Quine said:

"To seek what is 'logically required' for sameness of person under unprecedented circumstances is to suggest that words have some logical force beyond what our past needs have invested them with."

Similarly, Ludwig Wittgenstein warned: "If you imagine certain facts otherwise, describe them otherwise, than the way they are, then you can no longer imagine the application of certain concepts, because the rules for their application have no analogue in the new circumstances." ${ }^{7}$

There is of course nothing wrong with conducting investigations based on these two assumptions, but it is problematic that they are almost universally taken implicitly for granted, rather than being carefully articulated and argued for. It is far from self-evident that we can learn what is morally right and wrong in real life by reflecting on what would be right to do under quite different conditions that can never obtain. The following four tentative rules are proposed as a starting-point for a more active discussion on the scope of moral theories:

1) It is a respectable intellectual activity to explore the implications of various moral theories under the assumption that these theories as well as our moral intuitions cover all imaginable counterfactual circumstances.

2) It is also a respectable intellectual activity to explore the implications of such moral theories under various restrictions of their scope, not least their restriction to agents who are human (in the common sense of that word) and who act under circumstances that we do not have strong reasons to consider impossible.

3) The advantages of a broad scope for moral theorizing have to be weighed against the potential disadvantages. These include the risk that features incorporated in a moral theory to make it more plausible in unrealistic examples will also make it less plausible in real life.

4) The scope of a moral principle or theory needs to be explicitly stated and should preferably also be explicitly justified.

\section{Applied Ethics}

Applied ethics originated largely as the ethics of professions. The ethics of the medical profession goes back to antiquity. Engineering ethics has been discussed in professional societies since the 19th century. Research ethics also has a long 
tradition, but it did not gain much momentum until after World War II, in response to the nuclear bomb and atrocious experiments in Nazi concentration camps. In the 1970s, several other branches of applied ethics got off the ground, including business ethics, agricultural ethics, and computer ethics. Still today, most of applied ethics concerns the ethical responsibilities of a relatively small number of professions. Many other social areas with important ethical issues still lack a developed ethical discourse. This applies for instance to traffic safety, welfare provision, insurance, building and architecture, and foreign aid. ${ }^{8}$

Beginning around 1970, moral philosophers became increasingly engaged in applied ethics. The largest influx of philosophers took place in medical ethics, which has also been more affected by philosophical theory than most other areas of applied ethics. Philosophers working in this area often prefer the term "bioethics" (coined by Van Rensselaer Potter II in 1970) to the older term "medical ethics." 9 Philosophers brought with them a more extensive use of moral theory. Some of them also introduced issues and examples that healthcare professionals have reacted against as too remote from actual clinical practices, such as whether a physician should cause a patient to die in order to acquire organs for transplantations that would save two other patients. ${ }^{10}$

In the early 1990s, considerable resources for applied ethics were created through the research program Ethical Legal and Social Implications (ELSI) that was part of the Human Genome Project (HGP). ELSI was tasked to "anticipate the social consequences of the project's research and to develop policies to guide the use of the knowledge it produces." ${ }^{11}$ Apparently, many philosophers interpreted this as an opening for speculative and futuristic scenarios. As observed by Ari Schick:

"ELSI effectively inaugurated speculative bioethics in the regulatory
mode... attempting at once to be both future-oriented and practical; not
merely exploring in general terms the possibilities generated by future
technologies or treating them as material for philosophical thought experi-
ments, but pre-empting them and offering an image of the future in which
these technologies would produce benefits and few harms through the
implementation of proper guidelines and oversight."12

Similar funding initiatives in other areas, not least nanotechnology, provided additional opportunities to apply ethical theories to futuristic scenarios such as the use of nanotechnological devices to upload a brain on a computer. In this way, "a type of immortality could be achieved," and "such humans could travel at the speed of light and communicate directly from mind to mind." ${ }^{13}$ Speculative ethics has also been developed by philosophers working in other areas closely connected with human biology, such as cryonics, human enhancement, and transhumanism. ${ }^{14}$ In these areas, speculative examples are routinely offered as arguments on healthcare ethics and public policy, in contradistinction to the restrictedly theoretical use of similarly unrealistic examples in foundational moral theory, as discussed in the previous section.

\section{Mere Possibility Arguments}

A common argument for the use of unrealistic examples in applied ethics is that they may not be that unrealistic after all. Then their investigation can be subsumed under 
the common, and quite sound, argument that we need to investigate future technological developments before they actually take place.

"[C]ritics may believe that it is inappropriate or premature to consider such issues now. But we do not need to resolve that question here in order to take seriously the ethical and social issues advanced nanotechnology might raise. Even if advanced nanotechnology is a remote possibility, its scenarios appear so disruptive that they merit consideration... [I]f a political course had even a bare possibility to leading to a devastating war, costing the lives of millions, it seems that we are morally obligated to seriously consider that possibility, no matter how remote... [I]f history is any guide, most of our mid- and long-term predictions about technology will be overly optimistic or pessimistic. Many things we have today were once believed to be impossible or impractical—such as gas streetlights, residential electricity, telephones, highways, radio, airplanes, rockets, and even today's ubiquitous personal computer-so perhaps the prudent course is to treat most of these possibilities as reasonable until proven otherwise." 15

\begin{abstract}
"Some highly unlikely future events nevertheless have consequences that are so bad that the course of action with the best net benefits involves taking measures to prepare for such events. For example, the extremely slim chance that the Large Hadron Collider-the world's biggest particle collider, currently under construction-will result in the extremely bad consequence of destroying the earth has led to a lawsuit to halt its creation." ${ }^{\prime 16}$
\end{abstract}

The arguments referred to here are mere possibility arguments. By this is meant arguments "in which a conclusion is drawn from the mere possibility that the choice of an option, behavior, or course of action may lead to, or be followed by, certain consequences." ${ }^{17}$ There are two major variants of mere possibility arguments:

\author{
A negative mere possibility argument: \\ $A$ can lead to $B$. \\ $B$ should not be realized. \\ Thus, $A$ should not be realized. \\ A positive mere possibility argument: \\ $A$ can lead to $B$. \\ $B$ should be realized. \\ Thus, $A$ should be realized.
}

There are situations when a mere possibility argument forms an adequate basis for a decision. For instance, suppose that a member of a group of visitors to a weapons factory takes up a just finished pistol and puts it against his head, indicating that he will pull the trigger, just for the fun of it. Another member of the group says: "Don't! You can't know, it may be loaded." This is a mere possibility argument, which it seems reasonable to act upon. ${ }^{18}$ However, in other situations reliance on mere possibility arguments may lead to injudicious decisions.

A major reason for this is that in almost any decision, an unlimited number of mere possibility arguments can be constructed. Due to the ramified and often 
chaotic nature of causation, almost any action can possibly lead to extremely positive or extremely negative consequences. For instance, any new medical treatment can have unpredicted lethal side effects. Any new technological device can turn out to be useful for terrorists in unforeseen ways. And almost any action that we take can conceivably give rise to social conflicts that escalate, go out of control, and ultimately end up in war. Obviously, we cannot take all remote possibilities seriously. The mere possibility arguments that are referred to in ethical and political discussions are but a small selection of the arguments that can be constructed. It is not advisable to act upon the mere possibility arguments that have been put forward, without first considering whether other mere possibility arguments can be made. Perhaps there are even more plausible arguments pointing in the opposite direction.

The risk of a biased selection of mere possibility arguments is particularly great if resourceful or passionate stakeholders are mobilized on one side of the issue but not on the other. This can result in an unbalanced discussion, based on the false impression that all mere possibility arguments point in one and the same direction.

Unfortunately, once fears or hopes have been set in motion in this way, they are not easily extinguished, even if they are later shown to be utterly unfounded. One example of this is the debate on genetically modified organisms. In July 1974, soon after the first successful experimental modifications of DNA had been reported, the research community voluntarily deferred experiments with biologically active recombinant DNA molecules. ${ }^{19}$ After intense studies and discussions, it was agreed on a conference in February 1975 that the potential dangers were manageable. The moratorium was lifted and experiments were resumed, with safeguards that had been agreed upon. We now have massive evidence confirming that it was right to lift the moratorium. This technology can be used safely to achieve important gains in agriculture and, not least, in medicine. ${ }^{20}$ But still today, 44 years after the moratorium was lifted, there are activists who, contrary to the scientific consensus, uphold the picture of genetic modification as a new technology whose effects are largely unknown and potentially disastrous. This perception of the technology also continues to hold sway in a considerable part of the ethical literature on biotechnology. Scientific uncertainties that were overcome and laid to rest several decades ago still have a ghost life in the ethical literature. ${ }^{21}$

Transfusion medicine offers another example of the difficulties involved in reversing precaution. In the early 1980s, countries all over the world introduced lifetime deferrals of blood donations from men who have sex with men in order to avoid the use of HIV-contaminated blood in blood transfusions. Since then, new methods based on testing of the blood have been developed. ${ }^{22}$ A deferral period is still considered necessary to protect against recently acquired infections that will not be detected in antibody tests, but lifelong deferral is not needed. Quite a few countries have therefore shortened the deferral period to 12 months, and initiatives have been taken to reduce it to 3 months. ${ }^{23}$ However, many countries still apply a lifetime deferral period, although it does not provide any additional protection. Such policies contribute to the scarcity of donors, and they may also be conducive to homophobic sentiments and discrimination. ${ }^{24}$

"Ideally, precautionary policies would be applied when an uncertainty of risk exists, and its application modified or removed as new evidence is brought to light. Such an approach is rarely taken, however. In transfusion 
medicine, it has proven politically challenging to reverse a decision that was introduced for the purposes of protecting the public." ${ }^{25}$

Similar tendencies can be seen in other areas. For instance, as Ari Schick has pointed out, the ethical discourse on human enhancement has largely been detached from scientific and technological research. This puts "speculative bioethics at even greater risk of becoming a self-perpetuating program, unresponsive to the unpredictability that is at the heart of the scientific enterprise, and largely unaccountable for the role it plays within various 'communities of promise [and peril]'."26

The growth of speculative ethics may seem to be unstoppable. Once mere possibility arguments have been put forward, are they not impossible to ignore? To the contrary, I will argue that it is possible to write off many mere possibility arguments for the simple reason that what is possible may nevertheless be irrelevant for practical decisionmaking. For an example of a speculation that was rather promptly dismissed we can consider the "polywater" scare that circulated in 1969. Polywater, or polymerized water, was an alleged substance that would supposedly "grow at the expense of normal water under any conditions found in the environment," thus replacing all natural water on earth and destroying all life on this planet. ${ }^{27}$ Proposals were made to take precautions against this substance, but its alleged properties were highly implausible from a chemical point of view, and it was soon shown not to exist. And of course, polywater is just one of many constructible chemical doomsday stories. As Michael King and coworkers pointed out, "there may be a nonzero possibility that a chemical synthesized in a laboratory may initiate a chain-reaction that obliterates the ozone layer, destroying all life on earth." ${ }^{28}$ But as these authors also say, "prohibiting all chemical synthesis based on this possibility would be ridiculous." ${ }^{29}$ (Such a prohibition would put an end to all developments of new pharmaceuticals.) There is no obvious reason why polywater should be singled out for action among all the logically possible but scientifically highly implausible doomsday scenarios that can be constructed.

Another example, with considerable public health implications, is the supposition that MMR vaccine causes autism. This claim was put forward by Andrew Wakefield in a 1998 article, which is now known to be based on falsified data. ${ }^{30}$ But in spite of that information, antivaccination activists continue to claim that the vaccine may possibly give rise to autism. ${ }^{31}$ Concededly, science cannot prove with absolute certainty that this vaccine will never, in any person, causally contribute to autism. However, there are two other things that science can do, and has in fact already done. First, science can find out whether autism is more common among vaccinated than unvaccinated persons. Such studies have shown no difference between vaccinated and unvaccinated individuals. ${ }^{32}$ Second, science can tell us whether there are any valid reasons to suspect that the vaccine, rather than anything else that happens to a child, can lead to autism. There is in fact no such reason, or in other words: No one has been able to present a plausible mechanism for such an effect of the vaccine. Obviously, this does not prove that there is no such mechanism. There might be some potential mechanism that we are not aware of. However, the same is true about any other of the many events and influences in a young person's life. In the same sense that it is a (mere) possibility that the vaccine causes autism, it is also a (mere) possibility that autism is caused by riding the merry-go-round, playing with a skipping rope, or eating ice cream with strawberries. Most importantly, the same applies to the supposition that the vaccine has a protective effect against autism. ${ }^{33}$ 
Therefore, even if science cannot tell us with the absolute certainty of $1+1=2$ that there is no vaccine-autism connection, it has already provided sufficient reason to disregard that (mere) possibility in all practical deliberations.

The gist of these examples is that with the help of science and argumentative tools, we can disarm and defeat pointless mere possibility arguments. ${ }^{34}$ An important reason to do this work, and thereby remove unwarranted doomsday scenarios from the agenda, is that this place should be reserved for real problems to which our attention needs to be directed.

\title{
Neuroethics
}

Neuroethics is one of the areas of applied ethics that has been most affected by unrealistic scenarios. There is, unfortunately, some truth in the scathing criticism of the whole field that was launched a decade ago by a clinical neurologist and a medical anthropologist:

\begin{abstract}
"The moral scope of the new field of neuroethics is, in our view, limited... Neuroethicists are excessively enamored of the moral dilemmas they believe to be associated with the use of unproven functional imaging technologies to read minds and the use of yet-to-be-developed cognitive enhancement drugs to improve them. Moreover, they ignore issues of public health and social justice, such as the effects of lifelong exposure to toxins on our brains. Also ignored are the ethical challenges posed by traumatic brain injuries that are incurred in warfare. ${ }^{\prime 35}$
\end{abstract}

Similarly, Gilbert et al. ${ }^{36}$ describe neuroethics as "engaged in a speculative bubble, which may need to be deflated and rectified by grounding it in empirical evidence as available through the scholarly neuroscientific and medical literature."

Cognitive enhancement, mind reading, and remote control by means of implanted devices are among the most common topics in the speculative parts of neuroethics. ${ }^{37}$ In a paper critical of such speculations, Alfred Nordmann and Arie Rip wrote:

"Current discussions about ethics and nanotechnology take considerable interest in nano-enabled brain implants, mind-machine interfaces and related developments-such as the privacy issues that arise when thoughts can be read routinely from brain activity." ${ }^{38}$

After briefly criticizing the assumptions behind these concerns, they continued in the same paragraph:

"At the same time, other developments that demand ethical attention
receive much less attention. For instance, nano-enabled advances in deep-
brain stimulation can produce tremendous benefits for patients with
Parkinson's disease, but they can also be used to alter moods and even
personalities-but these issues are mostly overlooked by the nanoethics
community." 39

Thus, in the view of these authors, personality changes induced by deep brain stimulation are among the practically relevant issues that neuroethicists should turn 
to instead of other, more fanciful scenarios. Similarly, in 2014 Gilbert and Goddard criticized ethicists' preoccupation with "the fictional scenario of whether it is permissible to control human minds," arguing that this focus induces ethicists to "ignore the practical everyday postoperative significance of implanted patient selfhood, that is, who someone is, their sense of identity, and risk minimizing the importance of changes in who they are. ${ }^{\prime \prime 4}$ In another article, Gilbert and coworkers criticized neuroethical discussions on potential mind control via brain implants for optogenetic stimulation:

\footnotetext{
"Such speculation detracts from focusing on more immediate ethical needs related to application possibilities such as optogenetic restoration of lost vision, irreversibility of the procedure, and postoperative adverse effects on the patient's personality." ${ }^{41}$
}

These authors present personality changes due to implanted devices as an example of realistic and legitimate neuroethical concerns, in contradistinction to scenarios involving mind reading or mind control. As I see it, this is a reasonable appraisal. Brain activity takes place in exceptionally compact three-dimensional structures. The construction of a nondestructive brain-machine interface that interacts with more than a minuscule fraction of the brain's activity is a daunting task, and no credible way to do it seems to have been proposed. ${ }^{42}$ Even the more science-fictional scenarios, involving multiple sensors (somehow) inserted into the brain ${ }^{43}$ are very far from the complete reading of the mind that is presupposed in the more futuristic parts of neuroethics. As aptly pointed out by Berger, many of these scenarios are based on a primitive understanding of the brain as some sort of digital hardware, which is a gross misrepresentation of its biological nature. ${ }^{44}$

On the other hand, changes in personality and self-image are well-known side effects from interventions in the brain, such as tumour resection, ${ }^{45}$ brain artery aneurysm surgery, ${ }^{46}$ and surgical treatments of psychiatric disorders. ${ }^{47}$ Therefore, although undesired psychological changes seem to be rare in current applications of deep brain stimulation, ${ }^{48}$ concern for potential such effects is warranted when stimulation of other parts of the brain are considered, for instance in treatment of psychiatric conditions. ${ }^{49}$ The same applies when new and more advanced implants are introduced, such as bidirectional implants, which monitor brain activity as a means to optimize the stimulation. ${ }^{50}$ These risks have to be weighed against the benefits obtainable with deep brain stimulation, which include that many patients report becoming "more themselves in comparison to their previous life that was dominated by their obsessive-compulsive disorder." ${ }^{51}$ Notably, even when speculative exaggerations have been put aside-or perhaps in particular when this has been done-psychological effects of this and other treatments that affect brain function give rise to interesting philosophical issues. For instance, some psychiatric patients "regard elements of their illness as part of their identity." ${ }^{\prime 52}$ In such cases, it is no easy matter to determine which personality changes are desirable and which should be avoided. Both philosophical and clinical investigations are needed to make progress in this issue. 


\section{Conclusions}

To sum up, I have proposed that the use of unrealistic examples in ethics:

1) is justified in foundational ethics, but only under the (controversial) assumption that we need ethical principles and theories that would be applicable even under the extreme circumstances referred to in these examples,

2) is positively harmful in applied ethics whenever it leads us away from issues and aspects that are in urgent need of our attention,

3) is often engendered by mere possibility arguments that seem unconquerable but can in fact be written off with proper use of science and argument analysis, and

4) currently have an inordinate role in neuroethics, where they should yield place to problems that are relevant for the treatment and care of patients and for the development of new methods for diagnosis and treatment.

\section{Notes}

1. Abbott P. Philosophers and the abortion question. Political Theory 1978;6:313-35.

2. Whitehouse PJ, George DR. Book review: Ethical issues in neurology. New England Journal of Medicine 2008;359:2737-8. Rusconi W, Mitchener-Nissen T. The role of expectations, hype and ethics in neuroimaging and neuromodulation futures. Frontiers in Systems Neuroscience 2014;8:214. Gilbert F, Harris AR, Kapsa, RMI. Controlling brain cells with light: Ethical considerations for optogenetic clinical trials. AJOB Neuroscience 2014;5(3):3-11. Gilbert F, Viaña JNM, Ineichen C. Deflating the 'DBS causes personality changes' bubble. Neuroethics, Published online 2018, available at https:/ / link.springer.com/content/pdf/10.1007\%2Fs12152-018-9373-8.pdf.

3. Levi DS. Hypothetical cases and abortions. Social Theory and Practice 1987;13:17-48. Ward DE. Imaginary scenarios, black boxes and philosophical method. Erkenntnis 1995;43:181-98. Urquhart A. Complexity. In: Floridi L, ed. The Blackwell Guide to Philosophy of Computing and Information. Oxford, UK: Blackwell; 2004: 18-27. Hansson SO. The modal status of philosophy. Theoria 2006;72(3):173-6.

4. Oxford English Dictionary, online.

5. See note 3, Hansson 2006.

6. Quine WV. Review of Milton K. Munitz. Identity and individuation. Journal of Philosophy 1972;69:488-97.

7. Wittgenstein L. Zettel. Anscombe GEM, von Wright GH, eds. Anscombe GEM, trans. Berkeley: University of California Press; 1970, at 64e.

8. Hansson SO. Ethics beyond application. In: Takala T, Herissone-Kelly TP, Holm S, eds. Cutting Through the Surface: Philosophical Approaches to Bioethics. Amsterdam, UK and New York, NY: Rodopi; 2009: 19-28.

9. Potter VR. Bioethics: The science of survival. Perspectives in Biology and Medicine 1970;14:127-53. Reich WT. The word 'bioethics': Its birth and the legacies of those who shaped it. Kennedy Institute of Ethics Journal 1994;4:319-35. Reich WT. The word 'bioethics': The struggle over its earliest meanings. Kennedy Institute of Ethics Journal 1995;5:19-34.

10. Harris J. The survival lottery. Philosophy 1975;50(191):81-7.

11. Juengst ET. The human genome project and bioethics. Kennedy Institute of Ethics Journal 1991;1(1):714 , at 71.

12. Schick A. Whereto speculative bioethics? Technological visions and future simulations in a science fictional culture. Medical Humanities 2016;42(4):225-31, at 227.

13. McGee ME. Bioelectronics and implanted devices. In: Gordijn B, Chadwick R, eds. Medical Enhancement and Posthumanity. Dordrecht, The Netherlands: Springer; 2008: 207-24, at 208. On nanotechnological speculations, see: Gordijn B. Nanoethics: From utopian dreams and apocalyptic nightmares towards a more balanced view. Science and Engineering Ethics 2005;11(4):521-33. Nordmann A, Rip A. Mind the gap revisited. Nature Nanotechnology 2009;4(5):273-4.

14. Nordmann A. If and then: A critique of speculative nanoethics. Nanoethics 2007;1(1):31-46. 


\section{Sven Ove Hansson}

15. Lin P, Allhof F. Nanoscience and nanoethics: Defining the disciplines. In: Allhoff F, Lin P, Moor J, Weckert J, eds. Nanoethics: The Ethical and Social Implications of Nanotechnology. Hoboken, NJ: Wiley; 2007: 3-16, at 12.

16. Roache, R. Ethics, speculation, and values. Nanoethics 2008;2(3):317-27, at 323. A major reason why this argument could be laid to rest is that the planet is already under constant bombardment from outer space of particles with the same or higher energies than those produced in the Large Hadron Collider. Ball P. Nature News 2008 May 2; available at http://www.nature.com/news/2008/ 080502/full/news.2008.797.html (last accessed 23 Apr 2020). Ellis J, Giudice G, Mangano M, Tkachev I, Wiedemann U. Review of the safety of LHC collisions. Journal of Physics G: Nuclear and Particle Physics 2008;35:115004. Overbye D. Gauging a Collider's odds of creating a black hole. New York Times 2008 Apr 15; http://www.nytimes.com/2008/04/15/science/15risk.html (last accessed 23 Apr 2020). Ruthen R. Strange matters. Scientific American 1993;269(8):17.

17. Hansson SO. Great uncertainty about small things. Techne 2004;8(2):26-35, at 28.

18. See note 17, Hansson 2004, at 30.

19. Berg P, Baltimore D, Boyer HW, Cohen SN, Davis RW, Hogness DS, et al. Potential biohazards of recombinant DNA molecules. Science 1974;185(4148):303.

20. Berg P, Singer MF. The recombinant DNA controversy: Twenty years later. Proceedings of the National Academy of Sciences 1995;92(20):9011-3. Dunbar CE, High KA, Joung JK, Kohn DB, Ozawa K, Sadelain M. Gene therapy comes of age. Science 2018;359(6372):eaan4672.

21. Hansson SO. How to be cautious but open to learning: Time to update biotechnology and GMO legislation. Risk Analysis 2016;36(8):1513-7.

22. Busch MP, Kleinman SH, Jackson B, Stramer SL, Hewlett I, Preston S. Nucleic acid amplification testing of blood donors for transfusion-transmitted infectious diseases. Transfusion 2000;40 (2):143-59.

23. https:/ / barrie360.com/reducing-blood-donation-deferral-period-for-gay-men-being-called-lessdiscriminatory/ (last accessed 23 Apr 2020).

24. Wilson K, Atkinson K, Keelan J. Three decades of MSM donor deferral policies. What have we learned? International Journal of Infectious Diseases 2014;18:1-3. Wilson K, Atkinson KM, Fergusson DA, Brown A, Forster A, Murphy MSQ, et al. Problems with precaution: The transfusion medicine experience. Journal of Risk Research 2019;22(2):137-49.

25. See note 24, Wilson et al. 2019, at 144 .

26. See note 12, Schick 2016, at 228. See also: Racine E, Rubio TM, Chandler J, Forlini C, Lucke J. The value and pitfalls of speculation about science and technology in bioethics: The case of cognitive enhancement. Medicine, Health Care and Philosophy 2014;17(3):325-37.

27. Donahoe FJ. 'Anomalous' water. Nature 1969;224:198.

28. King M, Whitaker M, Jones G. Speculative ethics: Valid enterprise or tragic Cul-De-Sac? In: Rudnick A, ed. Bioethics in the 21st Century. Rijeka, Croatia: InTech; 2011:139-58, at 151.

29. See note 28, King et al. 2011, at 152 .

30. Deer B. How the case against the MMR vaccine was fixed. BMJ: British Medical Journal 2011;342 (7788):77-82. Deer B. How the vaccine crisis was meant to make money. BMJ: British Medical Journal 2011;342 (7789):136-42. Deer B. The Lancet's two days to bury bad news. BMJ: British Medical Journal 2011;342(7790):200-4. Harrison JA. Wrong about vaccine safety: A review of Andrew Wakefield's 'callous disregard'. Open Vaccine Journal 2013;6:9-25.

31. Hobson-West P. 'Trusting blindly can be the biggest risk of all': Organised resistance to childhood vaccination in the UK. Sociology of Health $\mathcal{E}$ Illness 2007;29(2):198-215. Dixon GN, Clarke CE. Heightening uncertainty around certain science: Media coverage, false balance, and the autism-vaccine controversy. Science Communication 2013;35(3):358-82.

32. Doja A, Roberts W. Immunizations and autism: A review of the literature. Canadian Journal of Neurological Sciences 2006;33(4):341-6. Maglione MA, Das L, Raaen L, Smith A, Chari R, Newberry S, et al. Safety of vaccines used for routine immunization of US children: A systematic review. Pediatrics 2014;134:325-37.

33. There is no reason to believe that the vaccine protects against autism, but it protects against another serious neuropsychiatric condition. One of the complications of measles is subacute sclerosing panencephalitis, a deadly disease with symptoms including personality changes and progressive mental deterioration that leads to a vegetative state.

34. For a more thorough discussion of these argumentative tools, the reader is referred to: Hansson SO. Coping with the unpredictable effects of future technologies. Philosophy and Technology 2011;24:137-49. Hansson SO. Evaluating the uncertainties. In: Hansson SO, Hirsch Hadorn G, eds. 


\section{Neuroethics for Fantasyland or for the Clinic}

The Argumentative Turn in Policy Analysis. Reasoning about Uncertainty. Cham, Switzerland: Springer; 2016, at 79-104.

35. See note 2, Whitehouse, George 2008, at 2738.

36. See note 2, Gilbert et al. 2018.

37. See note 2, Rusconi, Mitchener-Nissen 2008.

38. See note 13, Nordmann, Rip 2009, at 273.

39. See note 13, Nordmann, Rip 2009, at 293.

40. Gilbert F, Goddard E. Thinking ahead too much: Speculative ethics and implantable brain devices. AJOB Neuroscience 2014;5(1):49-51, at 49 and 50.

41. See note 2, Gilbert et al. 2014, at 4 .

42. Hansson SO. Implant ethics. Journal of Medical Ethics 2005;31:519-25, at 520.

43. Keskinbora KH, Keskinbora K. Ethical considerations on novel neuronal interfaces. Neurological Sciences 2018;39:607-13.

44. Berger F. Pour un renouvellement de l'encadrement éthique des neurotechnologies. In: Hirsch E, Hirsch F, eds. Traité de Bioéthique IV. Les Nouveaux Territoires de la Bioéthique. Toulouse, France: Éditions érès; 2018: 387-403.

45. Jenkins LM, Drummond KJ, Andrewes DG. Emotional and personality changes following brain tumour resection. Journal of Clinical Neuroscience 2016;29:128-32.

46. Pačić-Turk L, Šulentić T, Meštrović AH, Paladino J, Mrak G. Personality changes following brain artery aneurysm surgery. Acta Clinica Croatica 2016:55(4):565-78.

47. Eljamel S. Ablative surgery for depression. In: Sun B, De Salles A, eds. Neurosurgical Treatments for Psychiatric Disorders. Dordrecht, The Netherlands: Springer; 2015, at 87-94, at 92.

48. See note 2, Gilbert et al. 2018.

49. Johansson V, Garwicz M, Kanje M, Halldenius L, Schouenborg J. Thinking ahead on deep brain stimulation: An analysis of the ethical implications of a developing technology. AJOB Neuroscience 2014;5(1):24-33. Fuss J, Auer MK, Biedermann SV, Briken P, Hacke W. Deep brain stimulation to reduce sexual drive. Journal of Psychiatry and Neuroscience 2015;40(6):429-31.

50. See note 49, Johansson et al. 2014

51. de Haan S, Rietveld E, Stokhof M, Denys D. Becoming more oneself? Changes in personality following DBS treatment for psychiatric disorders: Experiences of OCD patients and general considerations. PloS One 2017;12(4):e0175748, at 23.

52. Meynen G, Widdershoven G. Why authenticity may be an inherent bioethical DBS concern. AJOB Neuroscience 2014;5(1):37-9, at 38. 